\title{
Phenomenology of a Projection Booth
}

\author{
Petra Dominkova \\ FAMU, Czech Republic
}

Tyler Durden: Why would anyone want this shit job? The Narrator: Because it affords him other interesting opportunities. (Fight Club 1999)

\begin{abstract}
Alfredo: You're like a slave and always by yourself. You see a film 100 times. You've nothing else to do. You talk to Greta Garbo and Tyrone Power like an idiot. You work like a dog. Salvatore: So why don't you change jobs? Alfredo: Because l'm a nitwit. (Cinema Paradiso 1989)
\end{abstract}

\begin{abstract}
Projectionists are left aside when the cinema apparatus is discussed. The following text is a rare attempt to put a spotlight on them, and the place they occupy: the projection booths. I will talk about the double split the projectionist went through during the history of cinema - split from the filmmaker and split from the spectator, I will discuss their relationship with the projector, the machine they necessarily need for their work, and will explore the miracles they may achieve by manipulation with it and the film reels. When switching the reels, splicing the frame into the film, or cutting the frame out of it, do the projectionists become a filmmaker? While we may talk about the relationship between a/ a filmmaker and camera and b/ spectator and camera, which is the relationship between spectator and projector? Last but not least I will contemplate how the projectionists are portrayed in the film.
\end{abstract}

Keywords: projectionist, projection booth, projection, screening, projector

\section{Introduction}

Digital technology has significantly influenced the way films are exhibited since the beginning of the $21^{\text {st }}$ century. Currently, film prints are obsolete, and films are mostly screened via so-called DCP and do not require the presence of a projectionist, who in a pre-digital era was a necessary accessory of each cinema. During the last decade, the number of digital cinema screens in Europe alone has increased almost ten times from 4.684 in 2010 to 41.040 in $2019 .{ }^{1}$ Regardless, projectionists (and, therefore, projection booths) still do exist, and - most likely - they always will. There are old prints that still circulate among cinemas, and also prints to be done and to be projected. The following text, therefore, should not be understood as referring to something long gone, but rather to something that is still - somewhere - a common situation: a projectionist occupying a projection booth.
"See, a movie doesn't come all on one big reel. It comes on a few," explains the Narrator in Fight Club (1999) to the audience while describing Tyler Durden's job. Yes, it is a known fact - when we go to the movie theater, there is someone already present, who is waiting for us with all these reels behind their back, and who is ready to screen the movie for us. But who are they? $?^{2}$ What do they do $?^{3}$ Where are they? And how are they portrayed in the movies? Over the following pages, I will contemplate the projectionist's tasks during the screening, define their relation with a projector, try to find where the enigma of a projection booth lies and share some notable instances of films that present a projectionist as one of the characters.

The scholarly literature about projectionists is virtually nonexistent. Film scholars write about the projections and projectors, but not about the projectionist. Not even the essay "The Intuition Space" (Markopulos 1998) contains any information about the projectionist despite the fact that the author is interested in their position within the cinematic apparatus. He asks "What does the filmmaker see? What does the film spectator see? What does the film projectionist see?". He responded to the first and second questions but failed to answer the third one. The projectionist as a concept, is, therefore, a tabula rasa.

\section{Who is the projectionist?}

The question "Who is the projectionist?" is not the same as the question "Who was the projectionist?" From the very beginning of cinematography until nowadays the projectionist went through the "double split" - the split from the filmmaker and the split from the spectator.

The camera of the Lumière brothers, pioneers of cinema, also served as a projector ${ }^{4}$, thus the Lumière brothers were both filmmakers and projectionists. Jan Křiženecký, the first Czech filmmaker/projectionist bought the machine from the Lumière brothers and in 1898 directed/showed his first films at the Exhibition of Architecture and Engineering in Prague. The setting of his films had been the same as the place where the screening eventually occurred. He did not change the machine, he did not change the place, and still, he fulfilled two tasks - to be a filmmaker and to be a projectionist. ${ }^{5}$

During the first years of cinematography, a projectionist usually stood among the audience, or just behind them. Unlike today he was not "hidden" in a projection booth somewhere "above" the audience; he shared the space with them. His experience of the film, therefore, needed to be different than today - simply by sharing the space with the viewers, he was more of a spectator than he is in the modern-day. 
Having had my own experience with projectionists as a former head of an art cinema in Brno, Czech Republic, I can confirm that when our projectionists wished to watch a film they were projecting, they left the projection booth and sat in the auditorium. It seems that they had to truly adopt the spectator's position for watching the film. It is as if there is something contradictory between being a projectionist and being a spectator: in the projection booth, one is only a projectionist.

In the film Sherlock Jr. (1924), the narrator criticizes Buster Keaton's wish to fulfill two professions - that of the projectionist and the detective: "Don't try to do two things at once and expect to do justice to both." We may use the same warning for the (imaginary) projectionist's attempt to be both spectator and projectionist at the same time. It is probably not possible - at least not today - since the projectionist does not share the space with the audience. ${ }^{6}$

The impossibility of being both the projectionist and the spectator is particularly interesting when considered in connection with the psychological aspects of screening. The Journal of Experimental Psychology published the article, "Rigidity in Cinema Seen From the Front Row, Side Aisle", whose author, James E. Cutting, describes what he names $\mathrm{La}$ Gournerie's paradox:

La Gournerie's paradox occurs in two forms: The first concerns viewing pictures either nearer or farther than the composition point but along the line extended between that point and (usually) the center of the picture; the second, and by far the most interesting and complex, concerns viewing pictures from the side at any distance [...] The composition point in cinema is at the location of the projector for film shot and projected with the same power lens. Because no viewer can sit in this location, La Gournerie's paradox, to greater and lesser degrees, is pertinent to all cinema viewers. (Cutting 1988, 323, 325)

Based on James E. Cutting's research, it seems that a projectionist should be the "ideal" spectator! Due to his position near the projector, he occupies the best seat that the movie theater offers. However, it appears that the projectionist is not only the "ideal" spectator, but he is also not a spectator at all.

There is also another facet that should be considered - at the beginning of cinematography, the projectionist had a much larger impact on the screening, since he could control the speed of it. Gerald Mast explains: "The skilled projectionist had to know how to turn the crank to make the action seem fluid and natural, just as the skilled cameraman did. The projectionist with artistic and rhythmic sensitivity could lyricize or comicalize scenes by cranking too slow or too fast." (Mast 1983, 116).

Today, the projectionist is no longer the filmmaker, he does not share the space with the audience, and his possibilities of influencing the screening are much more limited. So, who is today's projectionist? What do they do? If we ignore the other tasks that they usually do (like turning off the lights in the movie theater and drawing the curtains), their main task is to switch on the projector at the exact moment that one reel ends and the next one begins. For the screening to be smooth, it needs to be done in such a manner that the audience does not recognize that there is someone who does it. ${ }^{7}$ Their task is, in a sense, to be invisible. That is, however, impossible. The spectator is always "aware of the instrument-mediation that enables perception," as Vivian Sobchack insists (Sobchack 1991, 195). As a spectator, I am always aware of the fact that, first of all, it is not me who chooses what I will look at, that it is not mine, but someone else's (the filmmaker's/camera's) choice. Secondly, when I am sitting in a movie theater and turn my head, I can see this stream of light with shimmering dust in it, and I know this light comes from somewhere. That reminds me of the existence of still another instrument that serves as a mediator between the film footage and myself: the projector. In all probability I will never meet neither the cameraman of the film I am watching nor its projectionist, but, regardless, I know that they exist - that they are not invisible, even if they try.

\section{What does the projectionist do?}

First of all, the projectionists love their projector. One of the very few online sources about projectionists, The Mad Cornish Projectionist, contains a list of films in which a projectionist or a projector appears. Here, the primary interest is the type of projector used. For instance, we are informed that in Casino Royal (2006) "there is a short sequence set in a projection ro om with what looks like GK 21," and in The Shawshank Redemption (1994) "there is a brief scene in which one of the characters, Andy, gets beaten up in a projection box. Unfortunately there isn't a proper view of the projector," or that in Cleo de 5 a 7 "Cleo visits the box of a fleapit Paris cinema. Can't identify the machines". (Knight, 2021)

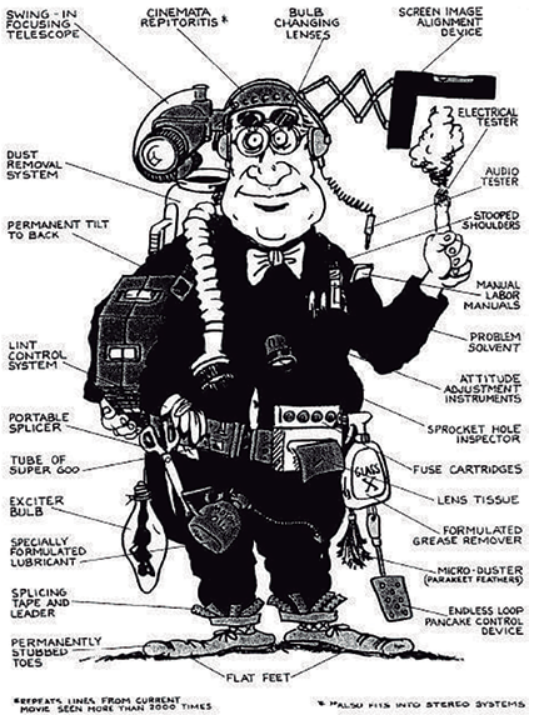

Image 1 - The complete projectionist 
What then is the relationship between a projectionist and a projector? On the website The Mad Cornish Projectionist, we can retrieve the picture with the title The complete projectionist, where the projectionist is blended with the projector and his retinas are compared to "bulb changing lenses" (see Image 1). However, this is not a rare occurrence. It seems that the fusion of projectionist and projector is quite common imagery. For instance, the character named Projectionist in the video game Bendy and the Ink Machine looks very similar to "the complete projectionist" (see Image 2). As is described on the Fandom website:

[Projectionist] has a projector as a head. Several long, hanging black wires (possibly film roll) are attached to his back and under his head, with the longest wire attaching to his right ankle, and another attached to his right arm. He has a film reel stuck in his left shoulder. [...] He has a speaker sticking out from the middle of his chest. (Bendy Wiki)

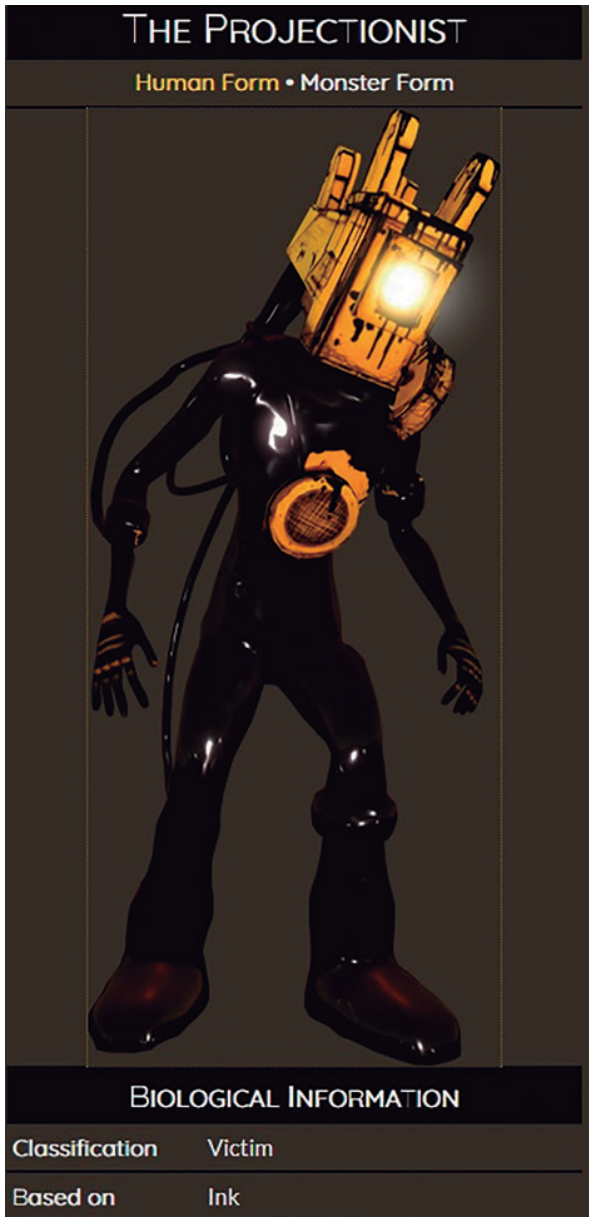

Image 2 - Projectionist
And we can even find projectionist-projector symbiosis elsewhere - the projectionist on Eric Fan's art piece is not a projector, however, he still blends with it, having a machine as an accessory to his hat (see Image 3). This desire not to have nor to master the machine, but to be the machine is discussed, for instance, by Allucquere Rosanne Stone:

I think of it as a kind of cyborg envy... The desire to be wired is part of the larger fantasy of disembodiment, the deep childlike desire to go beyond one's body. This is not necessarily a bad thing. Certainly for the handicapped, it can be very liberating. For others, who have the desire without the need, there can be problems. (Branwyn 1993)

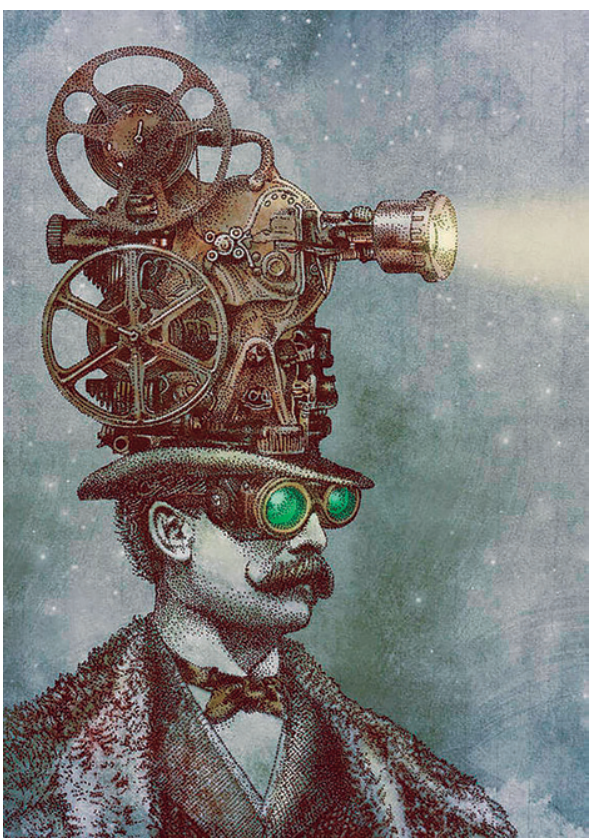

Image 3 - Projectionist (Eric Fan)

However, the projectionist is, indeed, not the projector. Both have their unique structure, their unique body. The projectionists could feel like the projector, and maybe they even want to be the projector, but they are not. Vivian Sobchack in her book The Address of Eye, traces the evolution of thinking about the relation between spectator/projector, filmmaker/camera, and spectator/camera. I would like to partly retrace this path and attempt to include the projectionist within this chain. Sobchack claims that there exist two mediated perception acts: "between the filmmaker, camera, and world [...], and between the spectator, projector, and world". (Sobchack 1991, 174)

But unlike the filmmaker, the spectator does not have any access to the projector. It is the projectionist who has the film's reels in his hands. He can completely 
change the audience's perception of the film. The projectionist in Fight Club (1999) splices one frame of pornography into a family film. "So when the snooty cat and the courageous dog with the celebrity voices meet for the first time in reel three that's when you'll catch a flash of Tyler's contribution to the film. Nobody knows that they saw it. But they did." Alfredo in Cinema Paradiso (1989) does something exactly the opposite: he cuts out the stills that include something "immoral" - usually characters kissing. In both cases, we witness the audience-within-film's reaction: confused parents and a crying girl in the first example and unsatisfied and upset viewers in the second one.

In these cases, the projectionist breaks the invisibility he is required to have and changes (destroy?) significantly the spectator's perception of the film. Nevertheless, one may argue that by adding or cutting the still(s) to/from the film the projectionist adopts the filmmaker's position - that this particularly changed film is, in a sense, his creation and a new film.

Similarly, when changing the order of the reels (indeed, the most common mistake of the projectionists), the projectionist could be said to become "the creator" of that film. Some time ago, I experienced a twisted screening of the film The Blind Swordsman: Zatoichi (2003). The projectionist changed the order of the reels, but the audience did not protest, as no one was aware of it. Since Asian films are rarely screened in the Czech Republic, the audience was willing to accept what seemed to be a distortion from a classic narration. Without refusing, they saw a different film than the one they had come to watch.

I witnessed the opposite situation during an initial screening of Pulp Fiction (1994). When a character that was supposed to have been dead for about twenty minutes appeared again on the screen - alive and in good condition - the audience immediately began screaming, whistling, and clapping their hands to inform the projectionist about what appeared to be his fault - the switched reels.

In The Address of Eye, we read

It is no accident that the normal mode of perceiving a film is by sitting in front of rather than behind the projector. In either position, the film can be perceived in its significance [...], but it is in the former position that the instrument loses most of its force as a mediating instrument and is best 'absorbed' into the perception act. (Sobchack 1991, 177)

To see the projector seems to be disturbing. An interesting scene occurs in Peeping Tom (1960) when Mark forces Helen to sit just next to the projector as he plans to screen for her the footage from his childhood. He does not let her sit in front of it as she had planned to. It is as if he wants her to see the projector in addition to the screen. Since the film is in a sense "about" a mediated world (it is not enough for Mark to see the fear on the faces of his victims, he wants to see their fear mediated on the screen) it would seem that Mark desires Helen to realize the mediation of the images from his childhood.
Elsewhere Sobchack explains the situation, when a projector fails to fulfill its role, using Don Ihde's term "hermeneutic relation":

The hermeneutic relation between the spectator and the projector, however, is of another sort. In its most extreme instance, the mechanism may almost completely fail in its mediating function - such as when the projected film loses its loop or slips in both the gate and our gaze. (Sobchack 1991, 188)

Based on Sobchack, in Bergman's Persona (1966) we can find an example of how this hermeneutic relation of the projector can be re-presented within the film. At one point we see the filmstrip from the position next to (or in?) a projector. Later, Sobchack discusses how the hermeneutic relations "occur in films that foreground the instrument-mediated nature of perception and its expression by representing the rupture of the smooth and synchronous reversibility of perception and expression." (Sobchack 1991, 188) But there is certainly a difference between our experience of the disruption of the "continuity and apparent motion" due to the flaw of a projector and our experience of the re-presentation of the flaw of a projector. The latter we may rather name "fake" hermeneutic relations. Our perception is different when we know we see something that just seems to be a "failing in mediating function". 9

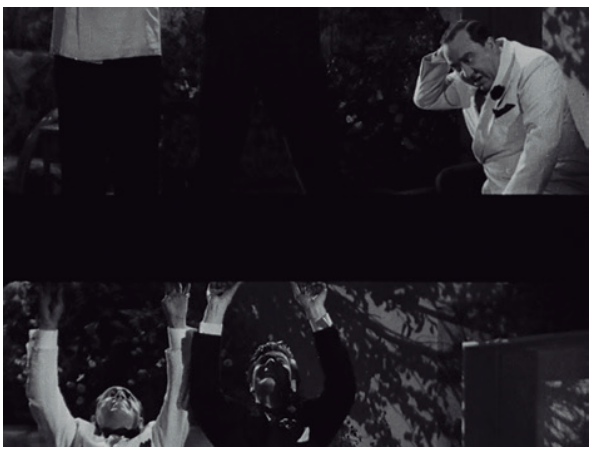

Image 4 - Hellzapoppin'

Besides Persona, we may find "fake" hermeneutic relations, for instance, in Hellzapoppin' (1941). The film has a complicated structure - it is a film within a film within a film - and what is more: the actors of this triple embedded film communicate with the projectionist of their film who appears in Hellzapoppin' (1941) as one of the characters ("Hey Louis! Rewind this film, will you", says Olson at one point to the projectionist who accepts his wish and rewinds the last scene). There is also implied the existence of the audience of this film within a film. Various presented "flaws" of a projector that occurred during the screening, however, could be experienced just as a "fake" hermeneutic relation by both audiences. Stanley Cavell describes one of these cases: 
I recall from Hellzapoppin' a moment in which either Olsen or Johnson, finding himself caught, as it were, by an off-sprocket film alignment (the frame separation dividing the top and bottom halves of the screen), hoists himself over the frame separation to rest wholly within the upper half of the screen.

(Cavell 1971, 125)

Although Stanley Cavell is not quite right considering the number of characters within the shot (all, Olson, Johnson, and Jeff are present) his description of the happening is accurate. The dialog among the characters during this scene deserves to be quoted in its entirety (also see Image 4):

The frame is flickering:

Ole Olson (O): Just the moment. We have a little problem with this film.

Chic Johnson $(\mathrm{CH})$ : That's Louis again.

O: Hey, Louis, would you keep your mind on your work? I'm getting a little seasick.

$\mathrm{CH}$ : So am I.

O: Hey, maybe we can handle this ourselves. Give me a hand.

The frame is divided into two horizontal halves, Chic kneels so he appears just in the upper half, Ole's and Jeff's bodies are divided - their heads and chests are in the lower part, legs in the upper:

Jeff: Where is Chic?

$\mathrm{O}$ (to $\mathrm{Ch}$ ): Hey, how did you get up there?

$\mathrm{Ch}$ (to $\mathrm{O}$ and Jeff): How did you get down there?

Due to the ridiculous activity of the characters, we know that we do not go through a hermeneutic relation of a projector, although it looks like one. If it were the flaw of the projector, the characters could hardly react to it. Hellzapoppin' (1941) is full of examples of presentations of "flaws" of a projector, but the behavior of the characters always reveals that it is, in fact, not our projector's flaws, but the projector-within-film's flaws. We face a more complicated situation in Fight Club (1999) towards the end of the film. We hear the sound of a projector and the frame is flickering. There is nothing to inform us that this is not the "flaw" of the projector. We can easily experience a hermeneutic relation to the projector although this is, in fact, a "fake" hermeneutic relation, not related to our projector (see Image 5).

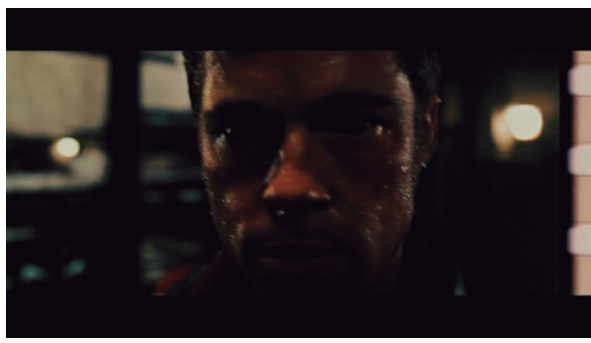

Image 5 - Fight Club

\section{How is the projectionist portrayed in the movies?}

A projectionist, as a character, appears in multiple films ${ }^{10}$, and even when their importance for the diegesis is mostly close to null, some films give more attention to them, even presenting them as the master of the movie theater. For instance, the projectionist in The Blob (1958) spends a just few seconds on the screen until he is devoured by the "blob", but his task is quite important. He has to be eaten first before the "blob" tries to devour all the spectators. We get the impression that had he not been eaten first, he could have the power to save the audience in the theater in a sense "his" audience. Similarly, the projectionist in The Tingler (1959) is attacked by the "tingler" after it had unsuccessfully attempted to attack one of the viewers. Instead of choosing another viewer, which would be much easier, the "tingler" rather chooses the projectionist - he, however, survives the attack and continues screening a film.

Projectionists-within-film are sometimes capable of "stealing" movies from the screen. The projectionist in Cinema Paradiso (1989) in one scene literally "frees" the movie from the movie theater and to soothe the audience's desire, he transfers the film from the screen into the square. The viewers beg Alfredo: "Let us in." As this is outside Alfredo's capability - he cannot let the audience in - he does what he can, he lets the film out. Quite the opposite occurs in Kings of the Road (1976) where the projectionist, due to the little mirror in front of the projector's lens, "doubles" the projection. The film, therefore, is on the screen, but "too dark in the middle," as a protagonist states, and also in his projection booth (indeed, because of the mirror). The projectionist projects the film into his projection booth; he is the only spectator of his private projection. In fact, there is not a more unlikely space where the projection could occur than in a projection booth. The screen is always opposite the projection booth and it is quite hard to imagine that the projection could occur literally behind the projector.

Confusion about the source of the projection we may find already in the early Edwin S. Porter film Uncle Josh at the Moving Picture Show (1902) that is probably the first film ever picturing the projectionist. At one point Uncle Josh, unsatisfied with the events in the film he is watching, wants to struggle with the film hero. He approaches the screen and tears it up in an attempt to find the projectionist. But the spectator in these early years was used to seeing the projectionist among the audience, i.e. opposite the screen. The film itself contains one scene where Uncle Josh is in front of the screen, and we can see the projection on his body. It would not be possible if the film had been projected from behind the screen, as in that case, we would see just the shadow of his body. 


\section{Projection booth}

The projectionist's kingdom is his projection booth, which indeed is an enigma - it is inside the cinema but outside the auditorium; it is a small space, which is crowded with huge machines; it is the room in the room; it is behind us but the stream of light that is coming of it is visualized in front of us. The spectator is aware of the existence of a projection booth but, however, is very rarely allowed to enter it.

When we look at the dictionary, we see that there is an emphasis on the word "small". Booth is "a small compartment or boxlike room for a specific use by one occupant: a telephone booth; a projection booth", "a small, temporary structure used by voters at elections" (Dictionary) or "a small space like a box that a person can go into: a phone booth, a polling booth" (Cambridge Dictionary). It seems that the projection booth is the biggest space that can be named as a booth. It is similar in the Czech language as well - a projection booth is kabina. Besides projection booth, this word can mean the cabin of the cable car, the cabin of the elevator, or a fitting room. Again - it seems that projection kabina is the largest kabina possible.

Maybe this is exactly the ambiguity of the space that grants a certain mystery to it. In a projection booth, things happen! The projection booth is often presented as a space connected with love and/or death. The projectionist in his projection booth kisses his girlfriend (Sherlock Jr., 1924; Desperately Seeking Susan, 1985; Cleo de 5 a 7, 1961; The Cleaner S02E03, 2009), he makes love with her (Night of the Comet, 1984; Come See the Paradise, 1990), or he masturbates (Kings of the Road, 1976).

Nevertheless, a projectionist could be even killed (or at least tried to be killed) in a projection booth (The Blob, 1958; The Tingler, 1959) and, on the other hand, s/he can be a killer (Evil Dead Trap 2, 1991; the female projectionist uses scissors originally used for cutting the stills from the reel for killing various women). Czech criminology, in fact, knows a case of a real projectionist-murderer, Jaroslav Papež, who was sentenced to death in 1967. He lured an 11-year old boy into his projection booth in Prague cinema Metro with the promise he could see a film that is not aimed at children. Instead, he stabbed him with the scissors. (Hrdelni zločiny 2001)

\section{Conclusion}

Towards the end of the film Projectionist (1970), the protagonist stays alone in the movie theater. He looks through the little window in the projection booth at the screen and sees himself. The screen became a mirror. A projectionist is at that moment also a spectator and a film hero. While we began the essay by talking about the "double split", from a filmmaker and spectator, here we have a "double connection", with a spectator (again) and with a film protagonist. Even when the projectionist is not a superhero, we have seen that he has superpowers and, indeed, deserves our attention.

\section{Final Notes}

${ }^{1}$ European Cinema Yearbook. Digital Screens Worldwide as of $1^{\text {st }}$ of January $2010 \mathrm{http}: / / \mathrm{www}$.mediasalles.it/ybk2010/index. $\mathrm{html}$ and as of 1st of January 2019 http://www.mediasalles.it/ ybk2019/index.html (accessed 27 March 2021).

${ }^{2}$ Considering the gender of projectionists, it should be mentioned that female projectionists are quite a rare occurrence - it is a profession mostly performed by men. From the sample of films where a projectionist appears there is only one woman, in the horror Evil Dead Trap 2 (1991). She uses her scissors for both cutting the stills from the reel and killing young women. One of the characters comments on her existence: "A female projectionist is like a blind spot in the equal opportunity employment law."

$* * *$

In the Czech language which typically utilizes different words for female and male workers in the professions (e.g. doktor/ doktorka $=$ male doctor/female doctor), only a few professions have the masculine form only and a projectionist is one of them. It is quite surprising considering that the Czech language has a word, for instance, for female crane operator (jerábnice) which is certainly a more physically demanding profession than a projectionist. If we try to create a female form from the masculine word promitač (projectionist) we get the word promitačka. This word exists in the Czech language but it means a projector.

${ }^{3}$ Projectionist John Marmo explains what he does not do: "We're not sitting up in the booth watching TV, drinking coffee, and reading girlie magazines." But he does not reveal what he does, except: "You're constantly on the go." In: Joe Sharkey, "Behind the Magic of the Movies," New York Times Dec 21, 1997, p. NJ1.

4 "This machine, amazingly enough, photographed, printed, and projected films, doing everything to a strip of celluloid that the cinema can do - except edit it." In: Gerald Mast, Film/ Cinema/Movie: A Theory of experience (Chicago, London: The University of Chicago Press, 1983), p. 10.

${ }^{5}$ The director Giuseppe Tornatore realized this "split" and tried to join these two professions together again in his film Cinema Paradiso (1989). Both projectionists who appear in the film - Salvatore and Alfredo - are the filmmakers/projectionists. Salvatore began his career as a projectionist, then he became a camera buff before becoming a famous filmmaker. Alfredo spliced together the scenes with kisses, that he was before forced by a vicar to cut outofrom various films, therefore creating a sort of "found footage" film.

${ }^{6}$ See the chapter Projection booth for closer examination of whetherithe spectators share the space with the projectionist or not. In fact, they do and they do not.

${ }^{7}$ The importance of this deed is referred to in the film Come See the Paradise (1990). The projectionist commits suicide, a new one is hired and he asks the manager of the movie theater: "What did he do? Miss the changeover?"

8 Don Inde defines "hermeneutic relation" in his book Experimental Phenomenology. He uses diagram Human $\rightarrow$ (machine-world) and explains that "Through the machine something (presumably) still happens elsewhere, only in this case [we] do[...] not experience the terminus of the intention which traverses the machine. [...] [The] primary experiential terminus is with the machine." (Inde 2012, 103) $\mathrm{He}$ places this relation in opposition to the situation (Humanmachine) $\rightarrow$ world when "The machine is "between" me and what is experienced and is in this sense a "means" of experience in the primary focus." (ibid, 101)

${ }^{9}$ Let's leave aside rare and very unlikely cases when during such a scene there would concurrently occur some issue with the projector and we as the spectator would experience real hermeneutic relation and "fake" hermeneutic relation of the projector at the same time (not talking about embodiment relation that we experience in each second of the projection).

${ }^{10}$ There are films that have a projectionist as a main character, few of them are even named Projectionist. The most recent case would be the Chinese film King of Peking (2017). 


\section{Bibliography}

Bendy Wiki. Monsters. The Projectionist. https:// bendy.fandom.com/wiki/The_Projectionist Last access on $1 / 04 / 2021$.

Cambridge Dictionary. https://dictionary.cambridge.org/ dictionary/english/booth Last access on 1/04/2021.

Dictionary. https://www.dictionary.com/browse/booth Last access on 1/04/2021.

Fine Art America. https://fineartamerica.com/featured/ the-projectionist-eric-fan. html?product=art-print. Last access on $1 / 04 / 2021$.

KODAK. http://www.kodak.com/US/en/motion/screen check/whatToDoP.shtml Last access on 1/04/2005

Branwyn, Gareth. 1993. "To Desire to be Wired." in Wired 1, no. 1 (Sep/Oct 1993). https://www.wired. com/1993/04/desire-to-be-wired/ Last access on 1/04/2021

Cavell, Stanley. 1971. The World Viewed: Reflections on the Ontology of Film. New York: The Viking Press.

Cutting, James E. 1987. "Rigidity in Cinema Seen From the Front Row, Side Aisle." in Journal of Experimental Psychology: Human Perception and Performance 13, no. 3: 323-334

Ihde, Don. 2012. Experimental Phenomenology: Multistabilities (2nd edition). Albany: SUNY Press.

Knight, Peter J. 2021. The Mad Cornish Projectionist. http://www.madcornishprojectionist.co.uk/index.php Last access on $1 / 04 / 2021$

Markopoulos, Gregory J. 1998. "The Intuition Space." in Millennium Film Journal no. 32 - 33 (Fall 1998): 70-75.

Mast, Gerald. 1983. Film/Cinema/Movie: A Theory of experience. Chicago, London: The University of Chicago Press.

Sharkey, Joe. 1997. "Behind the Magic of the Movies." in New York Times Dec 21, 1997: NJ1.

Sobchack, Vivian. 1991. The Address of the Eye: A Phenomenology of Film Experience. Princeton: Princeton University Press.

\section{Filmography}

The Blind Swordsman: Zatoichi. (Zatoichi, 2003). Directed by Takeshi Kitano, Japan.

The Blob. (1958). Directed by Irvin S. Yeaworth, USA.

Bulletproof Monk. (2003). Directed by Paul Hunter, USA.

Casino Royal

Cinema Paradiso. (Nuovo cinema Paradiso, 1989).

Directed by Giuseppe Tornatore, Italy / France.

The Cleaners S02E03. (2009). Directed by Richard Dobbs, USA.

Cleo from 5 to 7. (Cleo de 5 a 7, 1961). Directed by Agnes Varda, France.

Come See the Paradise. (1990). Directed by Alan Parker, USA.

Desperately Seeking Susan. (1985). Directed by Susan Seidelman, USA.

Evil Dead Trap 2. (Shiryo no wana 2: Hideki, 1991).

Directed by Izo Hashimoto, Japan.

Fight Club. (1999). Directed by David Fincher, USA. Hellzapoppin'. (1941). Directed by H.C. Potter, USA. Hrdelni zločiny. Zabijáci (3/3) Jaroslav Papež. (2001). Available at https://www.youtube.com/ watch? $\mathrm{v}=$ seDlqcxBtP4 Last accessed on 1/04/2021

King of Peking. (2017). Directed by Sam Voutas, China.

Kings of the Road. (Im Lauf der Zeit, 1976). Directed by Wim Wenders, Germany.
Night of the Comet. (1984). Directed by Thom Eberhardt, USA.

Peeping Tom. (1960). Directed by Michael Powell, Great

Britain.

Persona. (1966). Directed by Ingmar Bergman, Sweden. Projectionist. (1970). Directed by Harry Hurwitz, USA.

Pulp Fiction. (1994). Directed by Quentin Tarrantino, USA.

Purple Rose of Cairo. (1985). Directed by Woody Allen, USA.

Sherlock Jr. (1924). Directed by Buster Keaton, USA.

The Smallest Show on Earth. (1957). Directed by Basil

Dearden, USA.

Shawshank Redemption

Sullivan's Travelers. (1941). Directed by Preston

Sturges, USA.

The Tingler. (1959). Directed by William Castle, USA.

Uncle Josh at the Moving Picture Show. (1902). Directed by Edwin S. Porter, USA.

\section{Images}

Image 1

https://www.madcornishprojectionist.co.uk/home/

welcome-3/

Image 2

https://bendy.fandom.com/wiki/The_Projectionist

Image 3

https://fineartamerica.com/featured/the-projectionist-

eric-fan.html?product=art-print

Image 4

https://theseventhart.info/2020/04/25/hellzapoppin $-1941 /$

Image 5

Fight Club - screengrab 1:24:45 